\title{
Experimental investigation on the flexural and post-cracking behaviour of geogrid- reinforced concrete overlays \\ ${ }^{*}$ Correia, N. S. and ${ }^{2}$ Dalfre, G. M. \\ ${ }^{1,2}$ Department of Civil Engineering, Federal University of Sao Carlos, Sao Carlos, Sao Paulo, Brazil. Corresponding Author E-mail: ncorreia@ufscar.br \\ Tel: $\quad+551633519658$
}

Submitted on: 22/12/2020;

Accepted on: 21/01/2021

\begin{abstract}
Innovative materials are on the rise as alternatives to steel reinforcement in concrete structures. Recently, the use of polymeric geogrids as reinforcement elements has expanded into Portland cement concrete (PCC) overlays rehabilitation. Research conducted to date has indicated that the use of geogrids as reinforcement in concrete pavements shows both post cracking ductility and superior load capacity. Although this topic is not so explored in the literature, the use of geogrids in thin concrete overlays, pathway, pedestrian sidewalks and floating slabs is promising and gives a new employment area for the use of geogrid reinforcements. This paper presents an experimental investigation on the flexural behaviour, post-cracking and fracture energy performance of geogridreinforced concrete beams under four-point bending test. Different geogrids were embedded at onethird depth (from bottom) of concrete beam specimens $(500 \times 150 \times 150 \mathrm{~mm})$. The PCC mix was prepared using Ordinary Portland Cement (OPC grade 53) with compressive strength of $40 \mathrm{MPa}$. Results confirmed that the flexural performance and post-cracking resistance of the concrete beam specimens could be enhanced by the presence of geogrids, as evidenced by load-deflection response, crack mouth opening displacements and change in failure mode. Triaxial geogrids showed 11\% increase in flexural strength of concrete beam, highlighting the potential benefits of geogrids reinforcements in PCC overlays.
\end{abstract}

Keywords: Concrete overlays, Geogrid, Flexural behaviour, Post-cracking behaviour, Four-point bending test

\section{Introduction}

Innovative materials are on the rise as alternatives to steel reinforcement in concrete structures, such as fibre reinforced polymer bars, tendons, and grids (Tang et al. 2018). Recently, the use of geogrids as reinforcement elements has expanded into Portland concrete cement (PCC) structures as an alternative to steel reinforcements due to its high tensile strength and high structure ductility. PCC structures are usually reinforced with traditional steel mesh to provide the strength required to resist stresses caused by traffic loads, but there are still few limitations restraining their use, such as steel corrosion (Tang et al. 2008). Geogrid in concrete pavements, pathways, floating slabs or beams is promising and gives a application for the use of geogrid reinforcements, although this topic is not so explored in the literature.

Research conducted so far indicates that the use of geogrids as reinforcements in concrete overlays show both post cracking ductility and superior load capacity (Tang et al. 2008, El Meski and Chehab, 2014; Chidambaram and Agarwal, 2014; Itani et al. 2016, Tang et al. 2018, Meng et al. 2019). In the study of Tang et al. (2008), biaxial geogrids were installed at one-third depth of concrete beam specimens $(560 \times 150 \times 150)$ through third-point monotonic loading (rate of 1.2 $\mathrm{mm} / \mathrm{min}$ ). Results showed that geogrids added substantial post-cracking ductility and extended crack propagation after crack initiation and before concrete beam failure, while unreinforced beam failed in a brittle mode. 
El Meski and Chehab (2014) studied different types of geogrids (uniaxial, biaxial and triaxial) installed at one-third depth of Type I Portland cement concrete beam specimens $(530 \times 150 \times 150)$ under four-point bending test (rate of $0.12 \mathrm{~mm} / \mathrm{min}$ ). Results confirmed that all types of geogridreinforced concrete beams provided ductile post cracking behaviour, high fracture energy, high flexural strength, and large deflection. Still in the study of El Meski and Chehab (2014), the behaviour of biaxial and triaxial geogrids were comparable in terms of increase in load capacity and reduction in deflection capacity, although improvement in post peak behaviour was more pronounced in biaxial geogrid-reinforced beams.

Itani et al. (2016) evaluated the use of geogrids as reinforcement in thin concrete overlays using flexure tests to simulate traffic loading. Results showed that the reinforcement significantly enhanced overlay performance in the post-cracking regime in terms of strength, ductility and failure mode. In both monotonic and cyclic loading tests, reinforced samples cracked before unreinforced samples, however, reinforced samples controlled crack opening while unreinforced samples failure was of brittle mode.

Tang et al. (2018) examined the benefits of embedding geogrids in PCC beams evaluating flexural behaviour under a static four-point bending load. A triaxial geogrid was used in this study to reinforce plain concrete of normal strength. Strain measurements of the geogrids indicated instantly activation and mobilization upon the application of the flexural load, primarily contributing to alter post-cracking behaviour. According to Tang et al. (2018), due to geogrids relatively high strengthto-weight ratio, ease of handling and relatively lower cost, they have been increasingly investigated for potential use as reinforcements for PCC.

Tang et al. (2019) studied the potential benefits of embedding triaxial geogrids in concrete slabs using four-point bending tests recording load and midspan deflection data. Results showed that geogrid did not contribut to improve the concrete peak flexural strength, but carried additional load after crack initiation and were able to hold the reinforced concrete beam with macro cracks, suggesting concrete collapse failure delay. Hadi et al. (2020) evaluated the effect of geogrid reinforcement on the flexural fatigue behaviour of concrete pavements subjected to cyclic loads. Geogrid reinforced concrete specimens exhibited high resistance of crack mouth opening displacements, fatigue life increased up to $60 \%$ and flexural fatigue strength increased about $20 \%$. Al-Hedad and Hadi (2019) states that polymeric geogrid products have several structural advantages making them a potential alternative of steel reinforcement for PCC thin sections under relatively light loading conditions, including high tensile strength and excellent chemical resistance.

Besides benefits evidenced by findings from the aforementioned studies, the effectiveness of a geogrid in reinforcing PCC is still not well understood, especially regarding geogrid engagement and mobilization in PCC slabs under flexural loading (Tang et al. 2018). According to El Meski and Chehab (2014), some concerns still need to be investigated, such as different geogrids, reinforcement positioning, type of concrete, the interlocking between geogrids and coarse aggregates test speed and load type.

The present research aims to contribute with an experimental investigation on the flexural behaviour of different geogrid-reinforced concrete beams under four-point bending test. Uniaxial, biaxial and triaxial geogrids were embedded at one-third depth (from bottom) of concrete beam specimens to allow for comparison between unreinforced concrete beams. Post-cracking performance was also evaluated. 
LAUTECH Journal of Civil and Environmental Studies

Volume 6, Issue 1; March 2021

\section{Experimental Program}

\section{Materials}

The concrete mix used in this research was designed using Ordinary Portland Cement (OPC grade 53), water/cement ratio of the mixtures of 0.44 and nominal maximum size of the coarse aggregates $(9.5 \mathrm{~mm})$, which is smaller than geogrid opening aperture, allowing interlocking. For $1.0 \mathrm{~m}^{3}$ of concrete, the weights of the cement, sand, coarse aggregate were 514, 463, $726 \mathrm{~kg}$, respectively. The concrete mixture was designed to produce compressive strength of $40 \mathrm{MPa}$ at 28 days, according to ASTM C 39 (2020). Superplasticizers were not used. The geogrids used in this research (Figure 1) are polyester uniaxial, polypropylene biaxial and triaxial type. Table 1 presents characteristics of the tested geogrid provided by the manufacturer.

a)

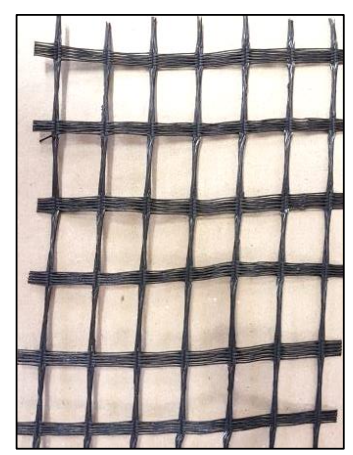

b)

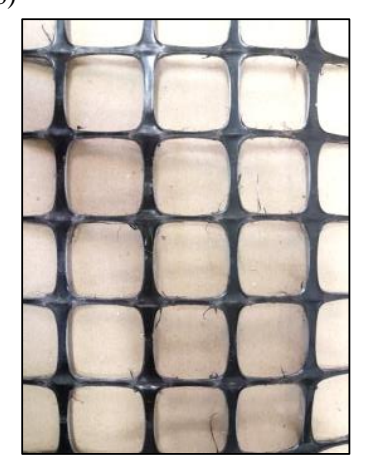

c)

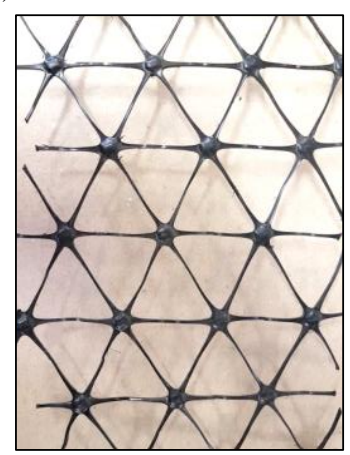

Figure 1: Geogrids: (a) Uniaxial; (b) Biaxial; (c) Triaxial

Table 1: Characteristics of geogrids.

\begin{tabular}{|c|c|c|c|c|c|}
\hline $\mathrm{S} / \mathrm{N}$ & Index Properties & $\begin{array}{l}\text { Standard } \\
\text { specifications }\end{array}$ & Uniaxial $^{\mathrm{a}}$ & Biaxial $^{\mathrm{b}}$ & Triaxial $^{\mathrm{b}}$ \\
\hline 1 & Aperture size $(\mathrm{mm})$ & - & $\begin{array}{l}25(\mathrm{MD}) \\
25(\mathrm{XMD})\end{array}$ & $\begin{array}{l}25(\mathrm{MD}) \\
33(\mathrm{XMD})\end{array}$ & 40 (diagonal) \\
\hline 2 & $\begin{array}{l}\text { Minimum Rib } \\
\text { Thickness (mm) }\end{array}$ & $\begin{array}{l}\text { ASTM D5199 } \\
\text { (2019) }\end{array}$ & 1.5 & 0.76 & 1.5 \\
\hline 3 & $\begin{array}{l}\text { Ultimate tensile strength } \\
\text { (kN/m) } \\
\text { Junction Efficiency (\%) } \\
\text { Radial Stiffness at @ } \\
0.5 \% \text { strain }(\mathrm{kN} / \mathrm{m})\end{array}$ & $\begin{array}{l}\text { ASTM D } 6637 \\
(2015)\end{array}$ & 33 (MD) & $\begin{array}{l}12.4(\mathrm{MD}) \\
19.0(\mathrm{XMD}) \\
93 \\
-\end{array}$ & $\begin{array}{l}93 \\
300\end{array}$ \\
\hline 4 & $\begin{array}{l}\text { Resistance to chemical } \\
\text { degradation }(\%)\end{array}$ & EPA 9090 (1992) & 100 & 100 & 100 \\
\hline
\end{tabular}

MD: machine direction (along roll length).

XMD: cross-machine direction (along roll width).

${ }^{a}$ www.huesker.com

${ }^{\mathbf{b}}$ www.tensar-international.com

\section{Specimen's preparation}

In order to evaluate flexural and post-cracking behaviour of geogrid-reinforced concrete beams compared to unreinforced concrete beams, four-point flexural bending test was conducted. Wood molds were constructed with internal dimensions of $500 \times 150 \times 150(\mathrm{~mm})$. Figure 2 illustrates concrete beam preparation. The geogrids were cut to fit wood mold area (Figure 2a) and its location was selected at one-third depth $(50 \mathrm{~mm})$ measured from the bottom of concrete beam specimens in order to be within the tension zone. Concrete was cast in three successive layers with proper vibration using a vibrating table (Figure 2b). At least two replicates per specimen (reinforced and unreinforced type) were produced. Specimens were conserved in an environmental chamber for 28 days before testing. 
a)

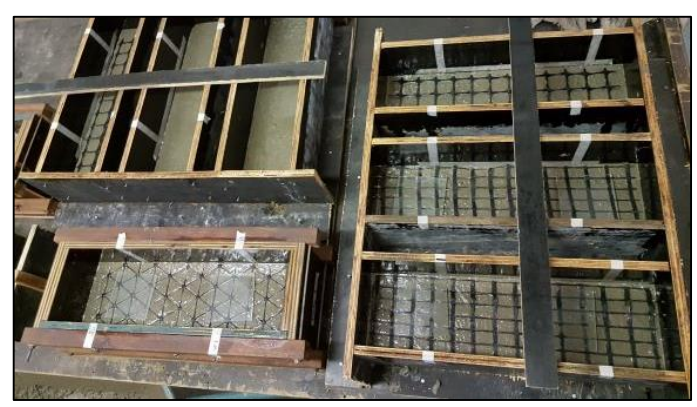

b)

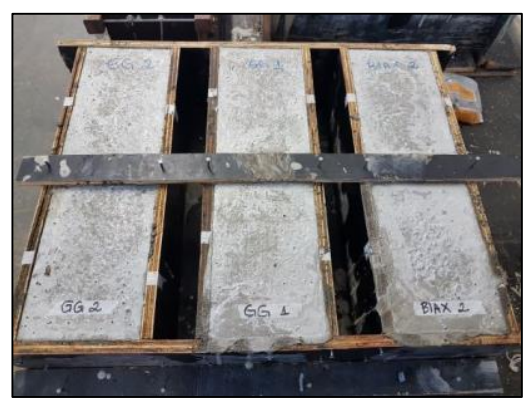

Figure 2: Specimen's preparation: (a) Concrete casting; (b) Concrete specimens.

\section{Flexural Loading Test Setup}

Flexure tests were conducted using four-point bending tests under monotonic loading, following ASTM C78 (2018). Four different test configurations were conducted, represented by unreinforced (UR), uniaxial geogrid (UX), biaxial geogrid (BX) and triaxial geogrid-reinforced (TX) concrete beams. The concrete beams were prepared in the laboratory and tests were conducted in a 60-ton servo-hydraulic universal testing machine, under displacement control ratio of $0.08 \mathrm{~mm} / \mathrm{min}$, until failure in flexure. A $10-\mathrm{mm}$ deep and $4.5-\mathrm{mm}$ wide notch was sawed across the centre of the bottom surface of the beams in order to induce failure cracking. The configuration of notched concrete beams test setup is shown in Figure 3a. A vertical linear variable differential transformer (LVDT) was installed to measure midspan deflection during loading (Figure 3b), as well as a horizontal LVDT to measure crack mouth opening displacement (CMOD) of the notch. Data was acquired to capture post-cracking behaviour.

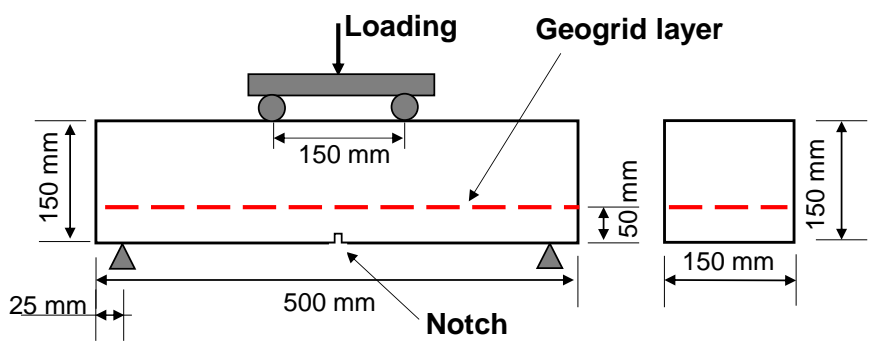

(a)

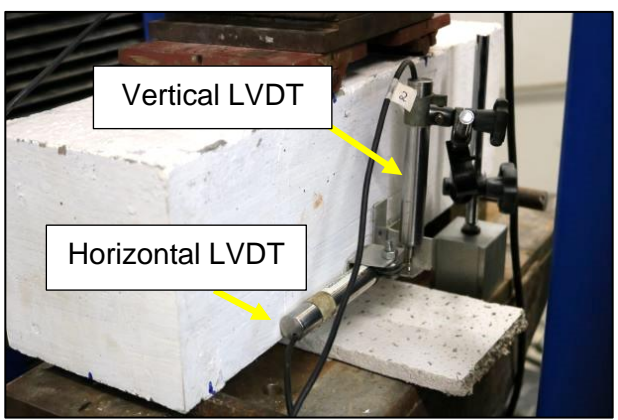

(b)

Figure 3: Configuration of loading and instrumentation setup: (a) Configuration of notched concrete beams; (b) Instrumentation 
LAUTECH Journal of Civil and Environmental Studies

Volume 6, Issue 1; March 2021

\section{Results and Discussion}

\section{Load-deflection curves}

The load-midspan deflection curves of reinforced and unreinforced concrete beams are presented in Figure 4. Results shows excellent repeatability of the replicate tests, as well as the increase in peak load of reinforced-concrete beams compared to unreinforced beams. Results of unreinforced concrete beams (Figure 4a) shows that specimens failed in a brittle mode immediately after peak, reaching peak loads of $30 \mathrm{kN}$ at failure. On the other hand, the load-deformation curves of reinforced-concrete specimens exhibited delayed failure and extra peak load in all cases. After load drop, reinforced-geogrid beams gained post-cracking ductility until cracks reached top surface beams, where failure was completed. Similar behaviour was evidenced in the research of Meski et al. (2014) using Biaxial and Triaxial geogrids, and in the research of Meng et al. (2019), although this last used Biaxial geogrids in pervious concrete beams.
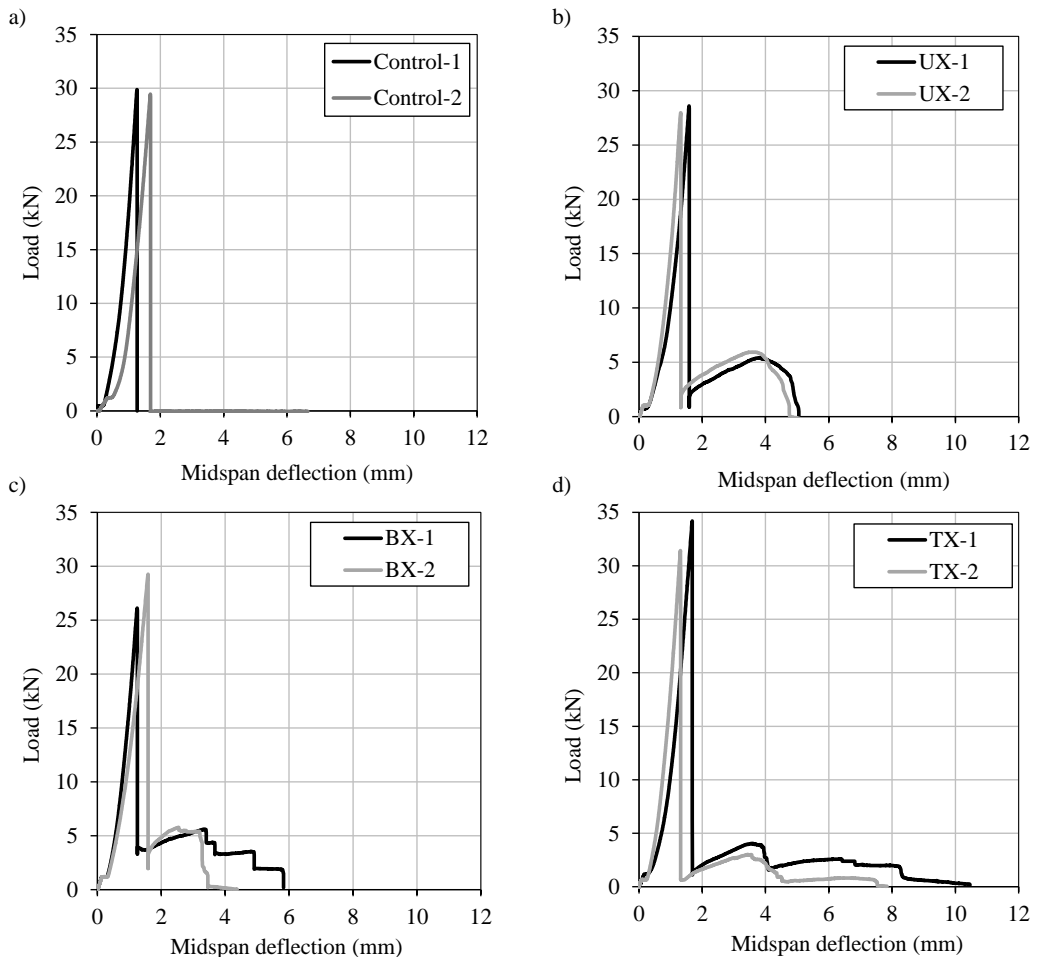

Figure 4: Flexure test load versus midspan deflection patterns and failure modes: (a) Control; (b) Uniaxial; (c) Biaxial; (d) Triaxial

Figure 5 shows a comparison of flexure test results (mean value) of all concrete specimens and Table 2 presents summary of load results. Comparing geogrid reinforced-concrete specimens, triaxial geogrid showed superior peak load, but reduced post peak load in comparison to biaxial and uniaxial geogrids. Both biaxial and uniaxial reinforced beams reached similar load capacity when compared to control specimens. In Figure 5, peak load of unreinforced beams occurred at maximum deflection of approximately $1.2 \mathrm{~mm}$, and in geogrid-reinforced concrete beams, peak load occurred at deflection of approximately $1.5 \mathrm{~mm}$. This behaviour reflects that geogrids did not contributed mechanically in the pre-cracking phase, as also observed by Masri et al. (2018). 


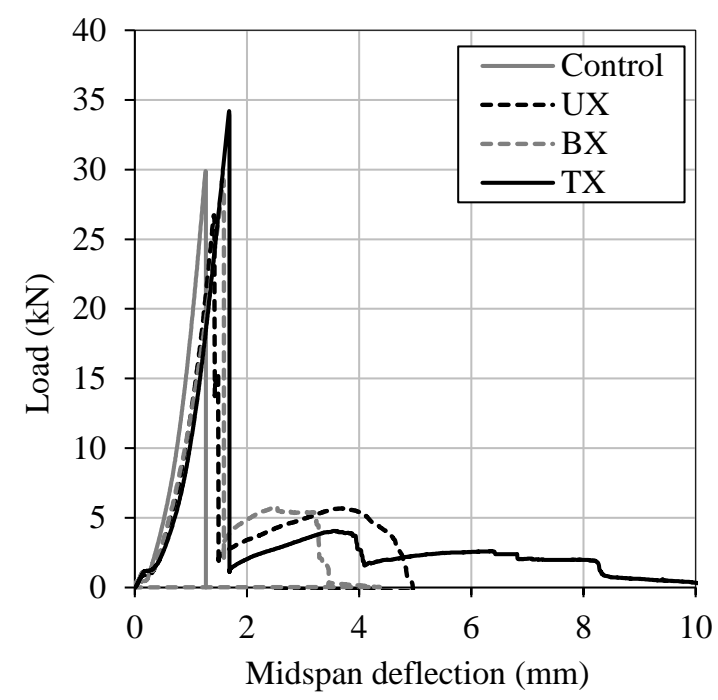

Figure 5: Comparison of flexure test results (mean value) of all concrete beams

Table 2: Summary of load results.

\begin{tabular}{cccccc}
\hline Characteristics & $\begin{array}{c}\mathrm{P}_{\max } \\
(\mathrm{kN})\end{array}$ & $\begin{array}{c}\text { Minimum load } \\
\text { after cracking } \\
(\mathrm{kN})\end{array}$ & $\begin{array}{c}\text { Post peak Load } \\
(\mathrm{kN})\end{array}$ & $\begin{array}{c}\text { Mediam } \\
\mathrm{P}_{\max } \\
(\mathrm{kN})\end{array}$ & $\begin{array}{c}\text { Percent } \\
\text { load drop } \\
(\%)\end{array}$ \\
\hline Control 1 & 29.9 & - & - & 29.35 & - \\
Control 2 & 28.8 & - & - & & - \\
UX 1 & 28.4 & 0.88 & 5.4 & 28.15 & 96.9 \\
UX 2 & 27.9 & 0.82 & 5.93 & & 97.1 \\
BX 1 & 26.1 & 3.3 & 5.57 & 27.7 & 87.4 \\
BX 2 & 29.3 & 1.98 & 5.58 & & 93.2 \\
TX 1 & 34.2 & 1.1 & 4.4 & 32.7 & 96.8 \\
TX 2 & 31.2 & 0.7 & 2.98 & & 97.8 \\
\hline
\end{tabular}

Figure 6 shows the observed modes of failure of beams during loading and at failure to understand reinforcing mechanism. Unreinforced concrete beams were immediately separated in two blocks each after failure (Figure 6a). In all reinforced beams cases, it was possible to visualize crack initiated at notch location and slow crack growth (compared to plain concrete beams). Load was completely absorbed by the geogrids, especially in the case of triaxial geogrid (Figure 6d) that remained intact as the crack initiated and did not crack all the way to the top. Another important aspect from the flexural strength analysis is the modulus of rupture $(\mathrm{R})$ of the specimens, which is calculated from the following equation:

$$
R=\frac{P . l}{b \cdot d^{2}}
$$

Where $\mathrm{P}=$ the maximum total load measured $(\mathrm{kN}) ; 1=$ span length of $45 \mathrm{~cm} ; \mathrm{b}=$ width of the specimen $(150 \mathrm{~mm})$; and $\mathrm{d}=$ height of the specimen $(150 \mathrm{~mm})$. 
a)

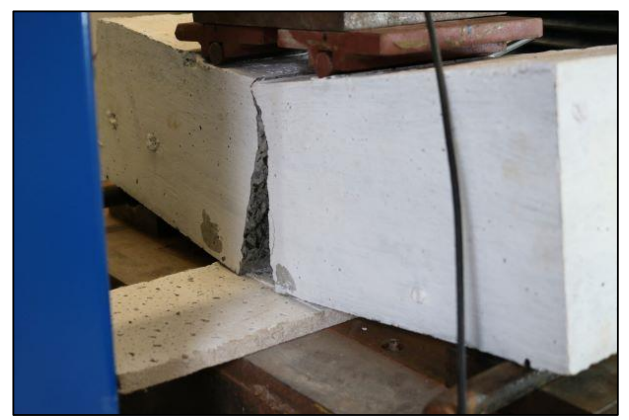

c)

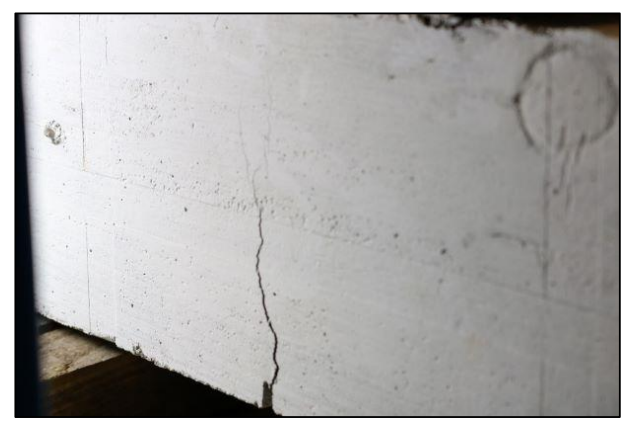

b)

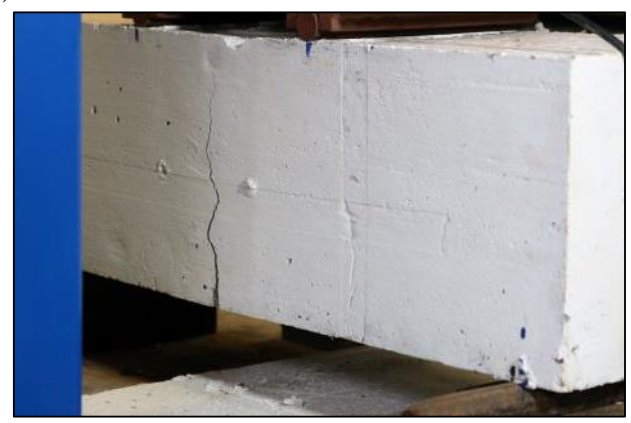

d)

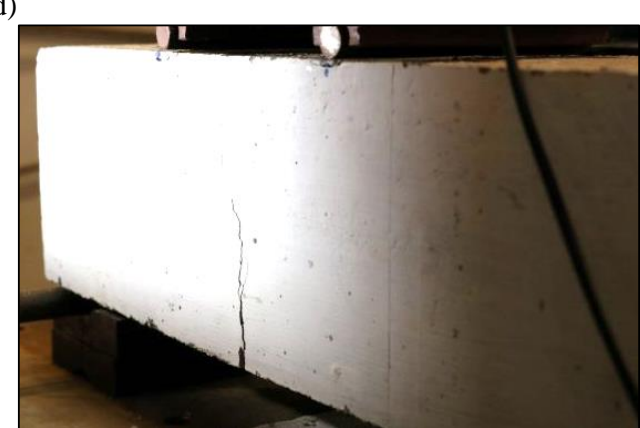

Figure 6: Failure of specimens: (a) Immediate brittle of control specimen; (b) Uniaxial; (c) Biaxial; (d) Triaxial

According to results presented in Figure 4, modulus of rupture was calculated for unreinforced and geogrid-reinforced beams. Table 3 summarizes flexural strength results. Results showed that the presence of the triaxial geogrid provided an increase in flexural strength to the concrete beams by approximately $11 \%$ and no significant improvement was observed for uniaxial and biaxial geogrids. This behaviour may be related to the superior tensile stiffness presented by the Triaxial geogrid when compared to Biaxial or Uniaxial geogrids, although Triaxial and Biaxial present same junction efficiency values. Results are consistent with those of El Meski and Chehab (2014) where an increase in flexural strength of concrete beam of $6 \%$ for triaxial geogrids was observed. Also consistent are the results of Tang et al. (2018) and Tang et al. (2019), where biaxial geogrids did not exhibit benefits in improving flexural strength of simply-support concrete beams under fourpoint bending.

Table 3: Summary of flexural strength results.

\begin{tabular}{|c|c|c|c|}
\hline Characteristics & $\begin{array}{c}\text { Flexural } \\
\text { strength, } \mathrm{R} \\
(\mathrm{kPa})\end{array}$ & Medium R $(\mathrm{kPa})$ & $\begin{array}{c}\text { Improve in } \\
\mathrm{R}\end{array}$ \\
\hline Control 1 & 3986.7 & \multirow[b]{2}{*}{3913.3} & \multirow[b]{2}{*}{ - } \\
\hline Control 2 & 3840.0 & & \\
\hline UX 1 & 3786.7 & \multirow{2}{*}{3753.3} & \multirow{2}{*}{0.96} \\
\hline UX 2 & 3720.0 & & \\
\hline BX 1 & 3480.0 & \multirow{2}{*}{3693.3} & \multirow{2}{*}{0.94} \\
\hline BX 2 & 3906.7 & & \\
\hline TX 1 & 4560.0 & \multirow{2}{*}{4360.0} & \multirow{2}{*}{1.11} \\
\hline TX 2 & 4160.0 & & \\
\hline
\end{tabular}

\section{Load versus CMOD and Fracture Energy}

Crack mouth opening displacements (CMOD) at the notch of the beams were measured during flexural tests and are presented in Figure 7. Table 4 presents a summary of displacement results and 
accumulated energy analysis. Unreinforced beams showed abrupt drop of load, along with a significant increase of CMOD measurements. Geogrid-reinforced concrete beams showed also an abrupt drop of load, but after drop, load was redistributed to the geogrids and CMOD increased gradually as geogrid ribs elongated until gradual rupture.

Table 4: Summary of displacement results.

\begin{tabular}{cccccc}
\hline Characteristics & $\begin{array}{c}\Delta \max \text { at } \\
\text { Pmax }(\mathrm{kN})\end{array}$ & $\begin{array}{c}\text { Medium } \Delta \max \\
\text { at Pmax }(\mathrm{kN})\end{array}$ & $\begin{array}{c}\Delta \max / \Delta \text { contro } \\
1(\%)\end{array}$ & $\begin{array}{c}\text { CMOD }(\mathrm{mm}) \\
\text { at Pmax }(\mathrm{kN})\end{array}$ & $\begin{array}{c}\text { Accumulated } \\
\text { Energy } \\
(\mathrm{kN.mm})\end{array}$ \\
\hline Control 1 & 1.26 & 1.24 & - & 0.236 & 153.4 \\
Control 2 & 1.23 & & & 0.071 & 216.4 \\
UX 1 & 1.59 & 1.45 & 16.5 & 0.010 & 52.9 \\
UX 2 & 1.31 & & & 0.056 & 40.9 \\
BX 1 & 1.44 & 1.50 & 12.9 & 0.045 & 45.8 \\
BX 2 & 1.57 & & & 0.023 & 35.1 \\
TX 1 & 1.68 & 1.59 & 19.7 & 0.015 & 70.7 \\
TX 2 & 1.5 & & & 0.018 & 52.6 \\
\hline
\end{tabular}

a)

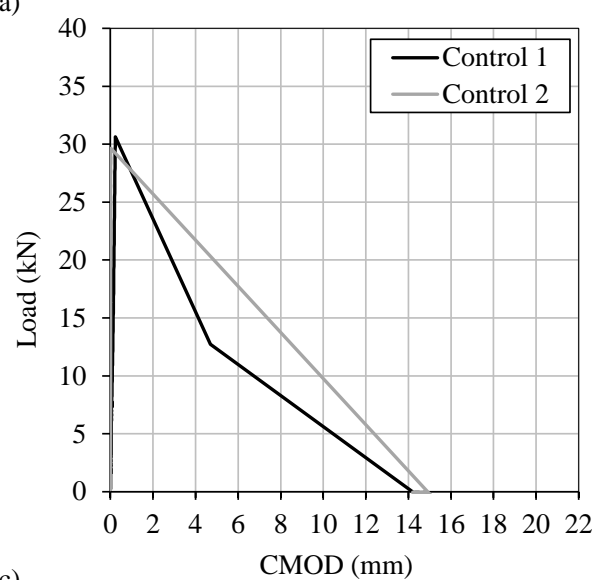

c)

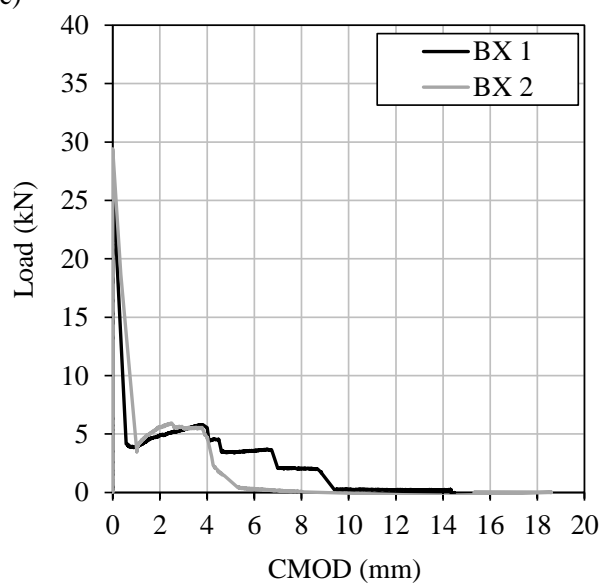

b)

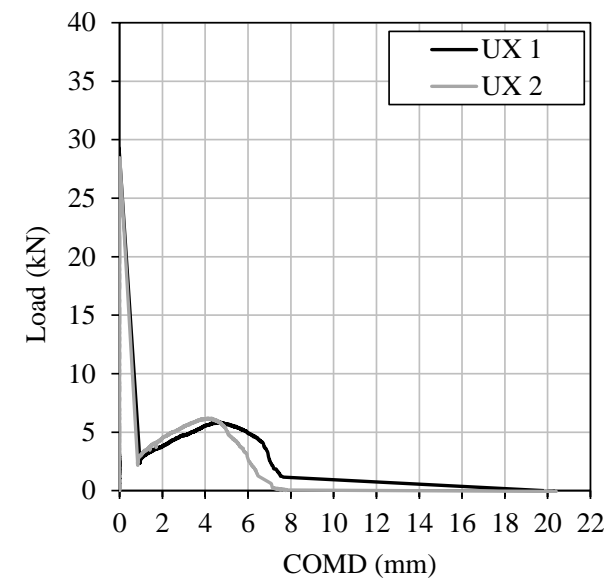

d)

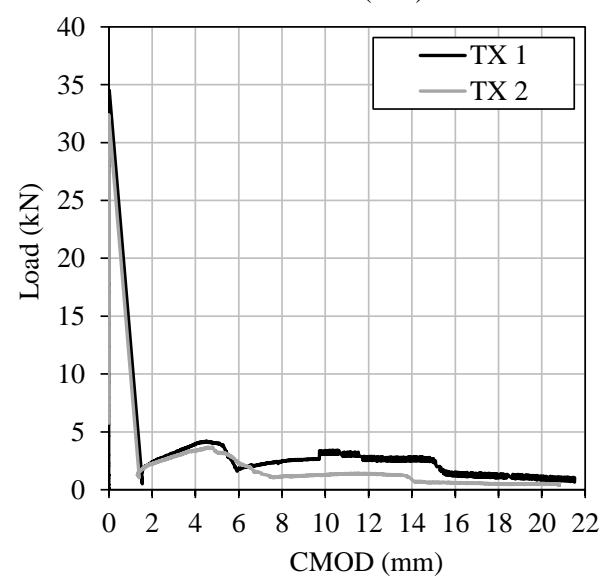

Figure 7: Flexural load versus midspan deflection patterns and failure modes. 
LAUTECH Journal of Civil and Environmental Studies

Volume 6, Issue 1; March 2021

Figure 8 shows that triaxial geogrid ribs were stretched after crack opening, illustrating the gradual rupture behaviour, in which multiple post peaks loads were registered. According to observations after the tests, geogrid failure occurred more in the ribs than on junctions, as observed by El Meski et al. (2014). In terms of fracture energy analysis, due to interlocking between geogrid and aggregates, reinforced samples were more resilient to crack opening, as also observed by Itani et al. (2016). In general, as observed by Tang et al. (2008), El Meski and Chehab (2014), Itani et al. (2016), Masri et al. (2019), Al-Hedad (2019) and herein, the main contribution of the geogrids in concrete beam were limited to providing post cracking ductility, some extra load capacity and change in failure mode.

a)

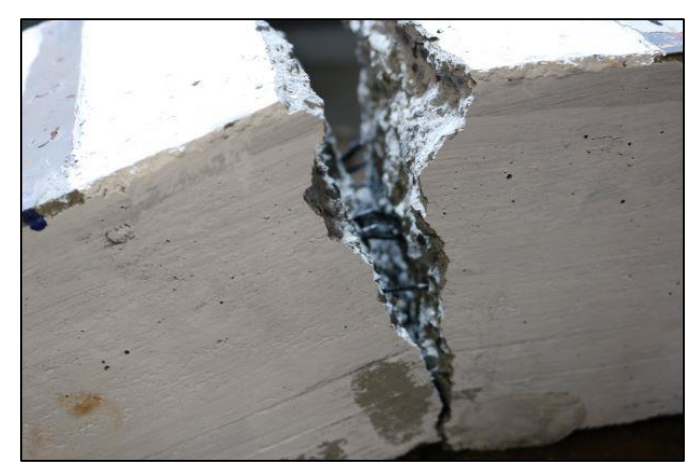

b)

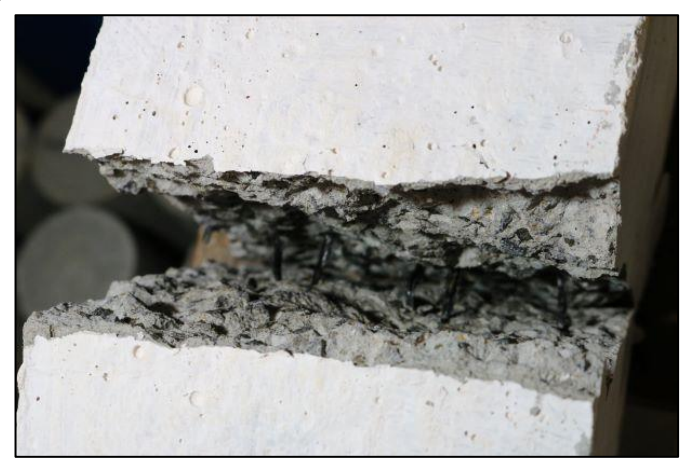

Figure 8: Stretching of Triaxial geogrid after reinforced-concrete beams failure:
(a) TX-1;
(b) TX-2

\section{Conclusions}

This experimental investigation was conducted to evaluate flexural behaviour and post-cracking behaviour of geogrid-reinforced and unreinforced concrete beams using four-point beam tests. Based on the findings, it is concluded that:

i. Unreinforced concrete beams failed in a brittle mode immediately after peak, while reinforced-concrete specimens exhibited substantial post-cracking ductility.

ii. The presence of triaxial geogrids provided an increase in flexural strength of the concrete beams by approximately $11 \%$, which was not evidenced for Uniaxial and Biaxial geogrids.

iii. Geogrid ribs were stretched after crack opening, illustrating the gradual rupture and crack delay behaviour. In terms of fracture energy analysis, due to interlocking between geogrid and aggregates, reinforced samples were more resilient to crack opening.

In general, the main contribution of the geogrids in concrete beams were limited to providing post cracking ductility, some extra load capacity and change in failure mode. Authors recommend that tests be carried out with other geogrids, concrete strength and load testing types. Extrapolations of these results should be performed with caution.

\section{Acknowledgment}

The authors thank the Laboratory of Geotechnics and Geosynthetics, the Laboratory of Materials and Components and the Laboratory of Structural Systems at the Federal University of Sao Carlos. 


\section{References}

Al-Hedad, A. S. A. and Hadi, M. N. S. (2019). Effect of geogrid reinforcement on the flexural behaviour of concrete pavements," Road Materials and Pavement Design, vol. 20, no. 5, pp. 1005-1025, 2019.

ASTM 5199 (2019). Standard Test Method for Measuring the Nominal Thickness of Geosynthetics, ASTM Int., 2019.

ASTM C39/C39M (2020). Standard Test Method for Compressive Strength of Cylindrical Concrete Specimens, 2020.

ASTM C78/C78M (2018). Standard Test Method for Flexural Strength of Concrete (Using Simple Beam with Third-Point Loading), 2018.

ASTM D6637 (2015). Standard Test Method for Determining Tensile Properties of Geogrids by the Single or Multi-Rib Tensile Method. 2015.

Chidambaram, R. Siva and P. Agarwal (2014). The confining effect of geo-grid on the mechanical properties of concrete specimens with steel fibre under compression and flexure, Construction and Building Materials, vol. 71, pp. 628-637, 2014.

El Meski, F. and Chehab, G. R. (2014). Flexural behaviour of concrete beams reinforced with different types of geogrids, J. Mater. Civ. Eng., vol. 26, no. 8, pp. 1-8, 2014.

EPA METHOD 9090A (1992). Compatibility Test for Wastes And Membrane Liners.

Itani, H.; G. Saad, and G. Chehab. (2016). The use of geogrid reinforcement for enhancing the performance of concrete overlays: An experimental and numerical assessment. Construction and Building Materials, vol. 124, pp. 826-837, 2016.

Hadi, Muhammad N.S., Abbas S.A. Al-Hedad. (2020). Flexural fatigue behaviour of geogrid reinforced concrete pavements, Construction and Building Materials, Volume 249, 2020,

Meng X.; Y. Chi, Q. Jiang, R. Liu, K. Wu, and S. Li. (2019). Experimental investigation on the flexural behavior of pervious concrete beams reinforced with geogrids, Construction and Building Materials, vol. 215, pp. 275-284, 2019.

Tang, I. Higgins X, and M. Jlilati (2018). Behaviour of Geogrid-Reinforced Portland Cement Concrete under Static Flexural Loading, Infrastructures, vol. 3, no. 4, p. 41, 2018.

Tang, X.; G. R. Chehab, and S. Kim (2008). Laboratory study of geogrid reinforcement in Portland cement concrete, Pavement Crack. Mech. Model. Detect. Test. Case Hist., no. June, pp. 769778, 2008.

Tang, X.; M. N. Jlilati, and I. Higgins (2019). Concrete Slab-on-Grade Reinforced by Geogrids, Proceedings, Geo-Congress 2019 GSP 307 42, pp. 474-480, 2019. 